\title{
IdeNTIFying Additional SElECtion CRITERIA FOR Physiotherapy STUdENTS IN Zambia.
}

\begin{abstract}
The purpose of this study was to investigate additional factors that should be included in the selection process of physiotherapy students in Zambia. A qualitative research design was chosen. Focused group discussions and semi-structured interviews were used for data collection purposes. The results of the study showed that besides pre-selection achievement, a number of non-academic variables should be included in the selection process of students because of their potential to influence academic performance.
\end{abstract}

\section{KEYWORDS: PRE-SELECTION CRITERIA, PHYSIOTHERAPY STUDENTS, ZAMBIA.}

\section{INTRODIICTION}

In the past, the number of students who sought admission into physiotherapy schools was much lower than is the case now (Nayer, 1992). Meanwhile, criteria used in the selection of prospective students into tertiary studies are increasingly being questioned (Loux, 1996). Those charged with the responsibility of selecting students from a large number of applicants are now faced with the problem of how to select students for the limited vacancies available.

Various pre-selection academic criteria are used for admission into the schools of physiotherapy. The use of pre-selection grades is widely accepted because they are readily available, considered reliable and they give tangible evidence of the applicants' potential for continued academic achievement (Nayer, 1992).

Physiotherapy programmes in most African countries use the results of the General Certificate of Education (GCE) or its equivalent. Generally, physiotherapy programmes require applicants to have acceptable pre-selection grades in Mathematics, Biology, Chemistry, Physics or Physical Science. Non-academic

\section{CORRESPONDENCE:}

\section{Esther M Nkandu}

University of Stellenbosch

Department of Physiotherapy

P.O. Box 19063

Tygerberg 7505

South Africa

Tel: (021) 938-9302 (w)

E-mail: en@gerga.sun.ac.za variables include interviews, psychological tests, aptitude tests and autobiographical letters.

The interview process gives an institution the opportunity to examine interpersonal skills, the suitability of the applicant and also assists in verifying information provided. Psychological tests are necessary when assessing the personality traits required for a specific profession. Beside pre-selection grades, the Allied Health Professions Admission Test (AHPAT) is commonly used in America (Nayer, 1992). Two types of letters are generally used namely those that are open ended, requesting a reference on a blank page, and the standardised recommendation form with specific questions to fill in. These letters are used to measure the writing skills of the applicants.

Numerous studies have shown that pre-selection grades play a major role in predicting academic performance. Kerr (1985) found a strong correlation between "O" level marks and academic performance amongst physiotherapy students in Ireland. Studies among medical students (Razali, 1996; Hoschl and Kozeny, 1997) and nursing students (Brennan et al, 1996) have also made similar conclusions. Two studies (Marais 1996; Mokwena 1997) done within Africa on physiotherapy students concluded that pre-selection grades were negatively related to academic performance. This was in contrast to a similar study done in Zambia (Nkandu, 1997).

Interviews have been proved to show little or no significance in predicting academic performance amongst physiotherapy students (Marais, 1996). Balogun (1987) found aptitude tests to be significant in first year performance in physiotherapy while letters of reference have been found to have a limited value (Nayer, 1992).

Loux (1996) stated that the use of scholastic achievements as the sole indicator of academic performance could give rise to enormous frustrations from applicants from disadvantaged or inferior schooling systems. Razali (1996) found that students who were satisfied with their choice of career faced fewer problems with their studies though their performance was equal to those who were less satisfied with their choice. Nkandu (1997) found that over 50\% of the students in her study sample in Zambia did not want to be physiotherapists. These students had originally applied for medicine. Some were not accepted on to the programme while others were sent off the programme due to inadequate academic performance. They then opted to study physiotherapy. In their final year of study, a number of these students reported that they were "beginning to enjoy the course".

Ginter and Dwinell (1994) considered other factors that could affect academic performance. Factors stressed in their study were loneliness and self-esteem. Additional factors were disadvantaged schooling systems, interest in a profession, students perception of the academic staff, burnout, physical disabilities and the quality of tertiary academic environment. Some studies (Corbet and 
Madorsky, 1991; George, 1995) have shown that disabled individuals aspiring to enter medical professions are still faced with significant barriers and that institutions assume that disabled people, though otherwise -qualified applicants, cannot meet the technical standards. These assumptions could be a lack of awareness of the potential of individuals with physical disabilities. George's (1995) study gave a classic example of Jim Post, a medical student with quadriplegia. The greatest obstacles to the disabled physicians, was the erroneous association, by their own profession, of physical disability with incompetence. Disabled medical students in Wu et al's (1996) study, performed as well as their able bodied colleagues.

\section{SELECTION CRITERIA}

Zambia has one physiotherapy school based in the capital, Lusaka, at the Evelyn Hone College. The School opened in 1972 and offers. a three-year diploma programme. The school receives a large number of applications each year. Currently, a degree programme is being introduced at the University of Zambia in Lusaka. The entry requirements into the physiotherapy school are as follows:

1. School leavers: GCE "O" levels with credits $(60-69 \%)$ in any four of the following subjects: Mathematics, Biology, Chemistry, Physics, Physical Science/Science and at least a pass in English language.

2. Mature age: 21 years and above:

- At least 3 GCE "O" levels credits and a recognised certificate in a relevant field.

- 2 years continuous work experience in a relevant field.

- Employer's sponsorship commitment if sponsored.

Most of the students who apply for this programme are those straight from secondary school and so admission is based mainly on selection criteria number one. Previously, the physiotherapy department, as part of the pre-selection procedure also conducted an interview.

\section{METHODOLOGY}

The purpose of this study was to identify additional factors, which should be considered when selecting students for physiotherapy training in Zambia. A qualitative research design was chosen for this component of the study. Focused group discussions and semi-structured interviews were conducted, with the groups of people involved in the students' selection and training programme. The theme of the discussions and structured interviews was: "What are the factors that should be considered in the selection of physiotherapy students?"

\section{STUDY SAMPLE}

This consisted of all five lecturers at the School of Physiotherapy at Evelyn Hone College, six senior physiotherapists involved with the clinical supervision of students at the University Teaching Hospital in Lusaka and three external examiners based in Lusaka.

\section{DATA COLLECTION PROCEDURES}

As it was a busy time of the year, it was not possible to have one focus group discussion with the lecturers. Each one of them gave 30-45 minutes of their time for one-to-one semi-structured interviews. Individual interviews were also conducted with three examiners for similar reasons. The clinical educators made time over their lunch period for a focus group discussion. This lasted for approximately one hour. Using voice recording facilities and note taking, data was collected. The notes taken described the focus groups or interview settings and also highlighted some non-verbal behaviour of the participants. The data was transcribed verbatim.

\section{DATA ANALYSIS}

Transcribing and categorising the information recorded, prepared the data for analysis. Analysis of the data was by categorising and comparing the different factors that arose under the given theme.

\section{RESIILTS}

Factors the lecturers felt should be considered in the selection of students for the physiotherapy programme are highlighted below:

The applicants needed to have very good GCE "O" level grades in English, Mathematics, Physical Science and Biology. Other contributions were:
LECTURER: "Selection of students into the physiotherapy programme should not be based only on the pre-selection academic achievements of the applicants. Physiotherapy is a profession where we work very closely with people. These applicants should therefore have good personalities and should be fluent in English".

RESEARCHER: "What do you consider a good personality?"

LECTURER: "The applicants should be well mannered, caring and should show respect to people especially those who are older... they should therefore have good communication skills".

LECTURER: "Those who want to study physiotherapy must fully understand what physiotherapy entails. A lot of students apply for courses without any knowledge of the profession. Applicants should have made contact with physiotherapists in their work environment prior to applying...so when they come for interviews they should bring essays showing why they want to study physiotherapy. This way we can also determine their writing skills".

LECTURER: "Applicants must enrol into the programme out of genuine interest and not because they don't have anything to do. They should be willing and able to care for the sick".

RESEARCHER: "How are you going to determine that the applicant has the traits you are looking for?"

LECTURER: "This is why we need to re-introduce interviews which the applicant must pass. We should also include psychological and aptitude tests".

Further, the lecturers felt that they were not adequately trained to meet the different needs of disabled students. Their comments were:

LECTURER: "Applicants need to be able bodied in order for them to cope with the demands of the profession".

RESEARCHER: "Are you not being biased against the physically disabled?"

LECTURER: "We are not being biased against them. As physiotherapy lecturers we are not adequately trained to meet their different needs". 


\section{CLINICAL SUPERVISORS/EDUCATORS}

The selection criteria stated by the clinical educators tallied with that outlined by the lecturers. Only one of them felt that technical drawing should be included on the list of recommended subjects. The reason given was that this would facilitate the students' understanding of treatment interventions like traction. Secondly it would help them understand the use and positioning of equipment in exercise therapy. The non-academic variables were that physically disabled applicants should not be accepted onto the programme because of the physical demands of the profession. An exception was made for partially sighted students,

"If a person is able to see and is competent why not?"

They further recommended that applicants should be physically active in sport, and that they should have healthy behavioural patterns. Two adverse behaviours were pointed out, namely smoking and alcohol consumption. They felt that, as future health promoters, physiotherapy students should be role models who should therefore not smoke or consume alcohol. Further still, they recommended that applicants should be medically fit though they did not reach a consensus on HIV positive applicants.

C/ED.1: "Students must have medical examinations prior to selection on to the programme"

RESEARCHER: "What if they are HIV positive?"

C/ED.1: "Well considering the length of the course maybe they should not be accepted"

C/ED.2: "No, the HIV status should not make a difference. Maybe if we all took HIV tests in this room some of us would be positive"

C/ED.3: "What if at the end of the training programme this person reaches a full blown picture of HIV/AIDS and dies?"

C/ED.4: "Well students might be negative on admission but might be positive during the training programme".

Other recommendations made were that since Zambia had more female physiotherapists than males there was a need to encourage a better gender balance.

\section{EXTERNAL EXAMINERS}

Though stated by all categories, the external examiners placed greater emphasis on pre-selection grades than those currently used.

\section{DISCUSSION}

Zambia currently has a large number of students with good grades applying for vacancies in training institutions. As most of the applicants into the physiotherapy programme qualify for the current set criteria, it makes the process of selection even more difficult. The recommendation to raise the selection criteria higher than that, which is documented, is acceptable, as the school will then have fewer students from which to choose. The country's problem is the limited number of institutions to which these potential students can send their applications. It is hoped that the introduction of a degree programme will help address the problem of limited vacancies.

A number of non-academic factors were raised which participants felt should be added to the selection process. The lecturers and clinical educators saw the need for prospective students to be able-bodied. They felt that they would not be able to meet the emotional and physical needs that the students would have during the course of training if they were not. Their statements of being "inadequately trained" and "physiotherapy being a physically demanding profession" seem to highlight the concerns of earlier studies (Corbet and Madorsky, 1991; George, 1995). Unlike the lecturers and clinical educators, Wu et al (1996) suggested that having disabled students was very important as they would bring with them a unique perspective and empathy because of their personal experience with illness. The marginalisation of disabled students goes against equal rights and opportunities (WHO, 1986). On the other hand, considering the inadequate number of staff at the Physiotherapy School in the Evelyn Hone College, the school may not be able to give the disabled students the extra attention they might require during the training programme. The implication of this scenario is that disabled individuals wishing to study physiotherapy will not be allowed on to the programme in spite of their having empathy, academic ability and interest in the profession.

The recommendation of having students with healthy behavioural patterns is a valid one though difficult to institute. Health professionals are key role players in health promotion and should be role models in health related behaviours. Nkandu and Amosun (1997) concluded that some of the students in their study sample indulged in unhealthy lifestyle behaviours and would not be ideal role models. While a correlation between behavioural patterns and academic performance has not been documented in physiotherapy, it is important for training programmes to empower students to enhance healthy behavioural patterns.

\section{CONCLUSION}

There is a need for committees that are charged with the responsibility of selecting physiotherapy students to consider non-academic variables in the selection process because of their potential to influence academic performance. These variables should include age, gender balances, interest (and the desire of the student to succeed in the selected profession), knowledge of the profession, communication skills and personality profiles. Health related behaviours should also be enhanced in order to make professionals who will be role models for their peers and in the communities where they will practice their profession.

\section{REFERENCES}

Balogun JA 1987 Predictive validity of the Allied Health Professions Admission Test. Physiotherapy Canada 39(1):39-42

Brennan AL, Best DG, Small SP 1996 Tracking student progress in a baccalaureate nursing programme: academic indicators. Canadian Journal of Nursing Research 24(2):85-97

Corbet B and Madorsky JG 1991 Physicians with disability, in rehabilitation medicineadding life to years. Western Journal of Medicine 154:514-521

George SC 1995 Ready and able. Journal of the New Physician 44:12-18

Ginter EJ and Dwinell PL 1994 The importance of perceived duration: Loneliness and its relationship to self esteem and academic performance. Journal of College Student Development 35:456-460 
Hoschl C and Kozeny J 1997 Predicting academic performance of medical students: the first three years. American Journal of Psychiatry 154:\$87-S92

Kerr K 1985 Pre-entry requirements and academic performance in the primary degree courses in physiotherapy at the Ulster Polytechnic. Physiotherapy 71(11):468-472

Loux AD 1996 The use of confidential reports for the selection of prospectus students for the Cape Technikon. South African Journal of Education 16(4): 194-200

Marais MR 1996 An evaluation of the outcomes of the students' selection methods into the BSc (Physiotherapy) degree programme at the University of the Western Cape. MSc (Physiotherapy) Thesis, University of the Western Cape

Mokwena K 1997 Matric rating: Is it predictor for student performance in physiotherapy at Medunsa? Abstracts International Congress of South African Society of Physiotherapy, Cape Town, Pg 19

Nayer M 1992 Admission criteria for entrance to physiotherapy schools: How to choose among many applicants. Physiotherapy Canada 44 (3):41-46

Nkandu EM 1997 The relationship between pre-selection criteria and academic performance of physiotherapy students in Zambia
MSc (Physiotherapy) Thesis, University of the Western Cape

Nkandu EM and Amosun SL 1997 Health beliefs and practices of health professional students of the University of the Western Cape. CHASA Journal of Comprehensive Health 8(3\&4):135-141

Razali SM 1996 Medical school entrance and career plans of Malaysian medical students. Medical Education 30:418-423

Wu SSH, Tsang P Wainapel SF 1996 Physical disability among American medical students. American Journal of Physical Medicine and Rehabilitation 75(3): 183-186

\section{Manual Concepts}

Education for Health Professionals

\section{CERTIFICATE IN ORTHOPAEDIC MANUAL THERAPY JANUARY \& JULY 2001 PERTH, WESTERN AUSTRALIA}

As an exciting new collaborative strategy

Manual Concepts and Curtin University are providing postgraduate education in manual therapy.

This comprehensive 4 week programme provides

clinicians with intensive tuition in an integrated approach to manual therapy to include mobilisation and manipulation, correction of muscle dysfunction and management of neural tissue pain disorders.

The programme is closely complemented by tutorials in functional anatomy, radiology and pain physiology.

This is a unique opportunity to be educated and closely supervised by our internationally respected team including Kim Robinson, Toby Hall, Bob Elvey, Jenny McConnell, Dr Peter O'Sullivan, Max Zusman, Professor James Taylor and osteopath Michael Monaghan.

Further information visit our website at www.manualconcepts.com

Email: info@manualconcepts.com

Mail: 278 Barker Road, Subiaco, Western Australia 6008

\section{Pilates training Course \& Equipment}

Two week Full-time course:

- $\quad$ Supervised Pilates workouts

- Observation

- Pracrical reaching

- Assisted teaching

- Lecture, theory \&application

Weekend workshops

- Offering clinical Pilates for physiotherapists \&

New York Pilates all levels.

Certification offered.

Natasha Madel, Studio Director \& the only certified Pilates instructor in South Africa, who has received her certification from Romana Kryzanowska. Romana Kryzanowska was a disciple of Joseph Pilates \& is a director of the Pilates studio teacher training program in New York.

The Pilates Method.is a series of exercises developed over seventy years ago by legendary physical, trainer Joseph Pilates. His unique practiced movements are, designed to stretch and tone your muscles while eliminating tension and strain from your joints. Learn how to isolate muscles \& fine tune movements, encouraging the body to reach its full potential

The Pilates Method cc

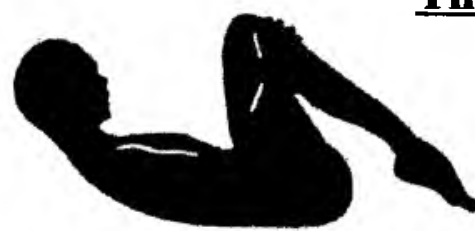

No $4,16^{\text {th }}$ Avenue, Houghton, JHB

Tel: (011) 4830768

Cell: 0834402599 